E3S Web of Conferences 1, 30003 (2013)

DOI: $10.1051 / \mathrm{e} 3$ sconf/20130130003

(C) Owned by the authors, published by EDP Sciences, 2013

\title{
Ecological Risk Assessments of Metal-containing Substances under Canada's Chemical Management Plan
}

\author{
J. Gauthier $^{1}$, A. Gosselin ${ }^{2}$ and M. Eggleton ${ }^{3}$ \\ ${ }^{1}$ Ecological Assessment Division, Environment Canada, Gatineau, Quebec, Canada, Joel.Gauthier@ec.gc.ca \\ ${ }^{2}$ Ecological Assessment Division, Environment Canada, Gatineau, Quebec, Canada, Anne.Gosselin@ec.gc.ca \\ ${ }^{3}$ Ecological Assessment Division, Environment Canada, Gatineau, Quebec, Canada, Marisol.Eggleton@ec.gc.ca
}

\begin{abstract}
There are approximately 3,000 metal-containing substances on Canada's Domestic Substances List (DSL). Approximately one third of these substances were identified for further action by the categorization of the DSL, a priority setting exercise completed in 2006 which was based on ecological and human health considerations. Subsequently, the first phase of the Chemicals Management Plan (CMP) was initiated and included activities such as the Challenge initiative to conduct screening assessments on the highest priority chemicals, including a few metal-containing substances. However, to assess the remaining elevated number of metal-containing substances identified as priorities $(\sim 1000)$ in the next phases of the CMP and that by 2020 , a process for finding efficiencies was established. For the risk assessment and risk management of metal-containing substances, efficiencies can be achieved by using a moiety-based approach in which all substances that contain a common metal moiety are assessed simultaneously as a group. This approach also allows for consideration of incidental releases of a given metal. Because ecological concerns were identified during the Challenge for cobalt, an early metal-moiety assessment is being undertaken in the second phase of the CMP for this metal. This work has been initiated and the draft screening assessment is expected to be published in November 2013.
\end{abstract}

Key words: Ecological risk assessment, metals, metalloids, cobalt

\section{Introduction}

There are approximately 23,000 substances on Canada's Domestic Substances List (DSL) of which 3,000 contain metals/metalloids. In 2006, Environment Canada and Health Canada completed the categorization of the DSL, a priority-setting exercise that led to the identification of over 1000 metal-containing substances as priorities for further action based on ecological and human health considerations (Eggleton et al. 2005). The substances identified are subject to screening assessment under the Canadian Environmental Protection Ac, 1999 (CEPA 1999) (Canada 1999) to determine if they pose a risk to Canadians and/or their environment, and, as appropriate, whether they should be subject to risk management action. Under the Government of Canada's Chemicals Management Plan (CMP) launched in 2006, all substances identified as priorities need to be addressed by 2020. The first phase of the CMP included activities such as the Challenge initiative for conducting ecological and human health screening assessments of highest priority chemicals, which included eleven metal-containing substances. The remaining metal-containing priorities need to be assessed during the next phases of the CMP, the second of which was announced in 2011 (Canada 2011a). The objective of this paper is to present and discuss the development / improvement of the approach for the ecological assessment of all metal-containing substances identified as priorities, with a focus on cobalt-containing substances (an early priority).

\section{Methods and Materials}

Process

The determination of ecological risk in a screening assessment conducted under CEPA 1999 includes several steps: (1) characterization of environmental entry, fate, and exposure: information is gathered on the ways in which substances enter and behave in the environment and on how non-human organisms can be exposed to the substances; (2) characterization of ecological effects: the potential for the substances to cause adverse effects to non-human organisms is evaluated; (3) risk 
characterization: the potential for the substances to cause harm to the environment is determined using multiple lines of evidence gathered during the assessment (e.g. persistence, bioaccumulation, risk quotient calculations, temporal trends, sensitive habitats or populations, etc.).

Screening assessments that were conducted under the Challenge initiative for high priority chemicals were done on a substance by substance basis. However, based on lessons learned from this initiative as well as from other regulatory initiatives under the CMP, Environment Canada and Health Canada established a process to find efficiencies to address the remaining priority substances by 2020 . One way to find efficiencies is to conduct assessments on groups of substances rather than on single chemicals. Among other criteria, groups can be formed based on similarities such as chemical structure (e.g. functional groups, mode of action) and/or industrial sector(s) involved with the substance. Using a group approach can streamline data collection, make analogue identification easier and allow for the use of read-across data, all of which can contribute to address data gaps. For metal-containing substances, a proposed approach is to group substances for assessment based on a common metal moiety of concern (e.g. cobalt) Indeed, since these substances may all release the metal moiety (e.g. the ion $\mathrm{Co}^{2+}$ ) under certain environmental conditions, they can all contribute to cumulative exposure and effects of organims to this metal moiety.

Results from the screening assessment of individual metal-containing substances that were conducted under the Challenge initiative are presented below, with a focused discussion on cobalt-containing substances as an example. The advantages of addressing a particular metal like cobalt in a moiety-based assessment rather than in a single substance assessment will be discussed.

\section{Results and Discussion}

Eleven metal-containing substances were identified as highest priorities for screening assessment under the Challenge initiative. These included four substances containing cobalt, CAS RN (Chemical Abstract Service Registry Number) in brackets: elemental cobalt (7440-48-4); cobalt chloride (7646-79-9); sulfuric acid, cobalt (2+) salt (1:1) (10124-43-3) and sulfuric acid, cobalt salt (10393-49-4). These substances were identified based primarily on concerns for human health, in addition to ecological concerns. In the ecological sections of the screening assessment for these cobalt-containing substances (Canada 2011b), site-specific exposure scenarios were developed for the major industrial sources of the four substances to the aquatic environment. Predicted exposure concentrations (PEC) were estimated near seven industrial facilities that include five nickel/copper/cobalt smelters and refineries, one cobalt alloy manufacturer and one manufacturer of a battery component. Predicted no-effect concentrations (PNEC) were based on aquatic toxicity data available for soluble cobalt compounds. Based on a risk quotient (RQ) analysis, i.e. comparing exposure and effect concentrations, there is likelihood that cobalt causes harm to aquatic organisms resulting from exposure to the total dissolved cobalt modeled releases from the use and/or production of the four substances (Table 1). However, the extent of the contribution of each of the four individual substances to the total exposure to the dissolved cobalt moiety remained uncertain. It was therefore concluded that the four substances that were under consideration are not individually causing ecological harm in Canada (Canada 2011b). Available exposure and source apportionment information was not sufficient to evaluate potential for harm to soil and sediment organisms related to the cobalt substances assessed, therefore no conclusions were drawn.

The ecological risks of the total dissolved cobalt moiety and relative importance of these four substances as contributors to the environmental loading and effects of total dissolved cobalt do warrant further examination. Consequently, it was proposed that these four and all other cobalt-containing substances that contribute to the total loadings of the cobalt moiety in the environment be considered in a moiety-based assessment early in the second phase of the CMP. The moiety-based assessment has been initiated as part of the CMP's Grouping initiative launched in February 2012 (Canada 2012) and a draft screening assessment is expected to be published in November 2013. Other metal- or metalloid-based groupings in this initiative are selenium-containing substances and boron-containing substances that are also proposed to be assessed in the second phase of the CMP (Canada 2012).

The advantages of addressing a particular metal like cobalt in a moiety-based assessment rather than on a on a substance by substance basis are numerous. First, in a moiety-based approach, it is possible to consider environmental monitoring data for total dissolved concentrations of the given metal in the aquatic compartment as well as other media. Indeed, these measured concentrations represent all sources that contribute to loadings of the given metal to the environment at a specific site. Second, it is possible to consider the incidental production and releases of a given metal (e.g. incidental releases from fossil-fuel power plants) that are not related to a specific CAS RN in terms of commercial activities. Third, grouping metal-containing substances facilitates and improves the assessment and management (if required) of these substances by identifying the major sectors/sites that potentially need measures to reduce exposure to the environment and/or humans. However, special consideration may be needed in the ecological assessment for certain subgroups of substances, for example organometallics that do not significantly contribute to dissolved concentrations of a given metal and/or may cause effects in their parent form. Other jurisdictions have also proposed similar approaches for assessing metal-containing substances (e.g. Europe, USA). 
Table 1. Risk quotients (RQs) calculated for key industrial exposure scenarios 1 in the aquatic compartment for the four cobalt-containing substances (Canada 2011b).

\begin{tabular}{|c|c|c|c|c|}
\hline Site No. & $\begin{array}{c}\text { Type of } \\
\text { facility/industry }\end{array}$ & $\begin{array}{l}\mathrm{PEC}^{1} \\
(\mu \mathrm{g} / \mathrm{L})\end{array}$ & $\begin{array}{l}\text { PNEC }^{2} \\
(\mu \mathrm{g} / \mathrm{L})\end{array}$ & $\mathrm{RQs}^{3}$ \\
\hline Site 1 & Smelter/refinery \#1 & 5.5 & \multirow{7}{*}{2.5} & $2.20^{4}$ \\
\hline Site 2 & Smelter/refinery \#2 & 5.5 & & 2.20 \\
\hline Site 3 & Smelter/refinery \#3 & 0.44 & & 0.18 \\
\hline Site 4 & Smelter/refinery \#4 & 4.3 & & 1.72 \\
\hline Site 5 & Smelter/refinery \#5 & 54.4 & & 21.76 \\
\hline Site 6 & $\begin{array}{l}\text { Cobalt alloy } \\
\text { manufacturer }\end{array}$ & 1.0 & & 0.40 \\
\hline Site 7 & $\begin{array}{l}\text { Manufacturer of battery } \\
\text { component }\end{array}$ & 1.7 & & 0.68 \\
\hline
\end{tabular}

\section{Conclusion}

Conducting assessments on groups of substances that can release a common metal moiety will provide a holistic efficient approach under the second phase of the CMP, in contrast with the assessment of individual metal-containing substances that was done in the Challenge initiative. There are numerous advantages to using a moiety-based approach, though sub-groups or certain individual substances may still need special consideration with the group assessment. For cobalt-containing substances, the assessment work has been initiated and a draft screening assessment is expected to be published in November 2013. The selenium and boron moieties are also proposed to be assessed in the second phase of the CMP. A moiety-based approach would likely be applicable for assessing these groupings and other remaining metal-containing priorities as well.

\section{References}

Canada 1999. Canadian Environmental Protection Act, 1999. S.C., 1999, c. 33, Canada Gazette. Part III, vol. 22, no. 3. Available from: http://www.gazette.gc.ca/archives/p3/1999/g3-0220 3.pdf

Canada, Dept. of Health. 2011a. Canadian Environmental Protection Act, 1999: Launch of the next phase of the Chemical Management Plan. Available

from: http://hc-sc.gc.ca/ahc-asc/media/nr-cp/_2011/2011128-eng.php

Canada, Dept. of the Environment, Dept. of Health. 2011b. Canadian Environmental Protection Act, 1999: Publication of Final Screening Assessment of Cobalt Chemical Substances in Batch 10 of the Challenge. Available from: http://www.ec.gc.ca/ese-ees/default.asp?lang=En\&n $=8 \mathrm{E} 18277 \mathrm{~B}-1$

Canada, Dept. of the Environment, Dept. of Health. 2012. Canadian Environmental Protection Act, 1999: Notice of announcement of planned actions to assess and manage, where appropriate, the risks posed by certain substances to the health of Canadians and the environment. Canada Gazette, Part I, Vol. 145, no. 41 p. 3125-3129. Available from:

http://www.gazette.gc.ca/rp-pr/p1/2011/2011-10-08 /html/notice-avis-eng.html\#d127

Eggleton M, Rudnitski K, Couillard Y, Gauthier J, Goulet R, Schnabel S, Costa P, Doyle P. Setting Priorities for the Ecological Risk Assessment of Inorganic Metal-containing Substances in Canada. 2005. Extended Abstract submitted for "13th International Conference on Heavy Metals in the Environment", Rio de Janeiro, June 5-9 2005. 